\title{
Influence of Sports Fans Identification on the Relationship between Media Use and Self-Esteem
}

\author{
Alaaeldin H. Mohamed ${ }^{1}$ \\ ${ }^{I}$ Department of Sport Management, Faculty of Physical Education, Damietta University, Egypt.
}

\begin{abstract}
The current research aims at investigating the relationship between media use and self-esteem by testing fan identification as a moderator between both of them. The author hypothesized that fan identification would be positively associated with measures of media use and self-esteem and also moderate the relationship between these 2 variables. Data gathered from sports fans ( $\mathrm{N}=141$ Egyptian participant) through Facebook groups relating to sports fans confirmed the author's expectations that sports fans' use of 4 types of mediaprint, broadcast, online, and mobile phones - and that fan identification moderated the relationship between three types of media use (broadcast media, online media, and mobile phones) and self-esteem.
\end{abstract}

Keywords: Types of media, Sports fans, social identification theory

\section{INTRODUCTION}

Not only do sports fans attend games in person, but they use a wide variety of media including print, broadcast, the Internet, and mobile phones as well to keep up with their favourite teams and individual players. Through print media, they find out about their favourite teams and players. Broadcast media, including television and radio, enable them to watch live games; especially when they are not able to attend it in person. Today, there are so many sports programming on some television networks that telecast sporting events in their line-up, in addition to the cables where channels keep telecasting sports programs all day. Besides, the televised sports played at the professional, college, and high school levels are endless (Phua, 2010) 
In the current study, I looked at sports fans' use of four types of media-print, broadcast, online, and mobile phones - to examine the relationships between media use, fan identification, and collective self-esteem. By doing this, I sought to determine whether fan identification has an effect on media use and self-esteem and, if so, which among the four types of media has the most significant effect. Using social identity theory (Tajfel, 1978) as a theoretical framework, I attempted to extend previous research by investigating the influence of the fan identification on the relationship between the four types of media use and self-esteem.

\section{LITERATURE}

According to Bryant and Raney (2000), "televised sports permeate modern life from the family room to the newsroom and boardroom" (p. 153). With the proliferation of the Internet in the 1990s, sports fans also began to check online for the latest statistics and other information about their favourite teams and players. A 2008 poll showed that sports fans accounted for $19 \%$ of overall Internet users in the United States, and they also spent more time online, engaging in activities such as playing fantasy sports, participating in fan forums, watching streaming video, and shopping for sports memorabilia (Sachoff, 2008). On most popular sports Web sites, there are discussion forums, message boards, news, game updates and schedules, streaming video, live audio, commentary, stats, and more devoted to specific teams and players (Real, 2006). In August 2009, sports Web sites like Yahoo! Sports, ESPN Online, Sports Illustrated Online, and Fox Sports on MSN ranked among the top 25 most visited sites for Internet users in the United States (Marketing Charts, 2009). In addition, social-networking sites like Facebook now allow sports fans to join team-specific groups and add applications where they can chat with other fans, and microblogging sites like Twitter enable them to send and receive updates about their favourite teams and players. (Additionally, YouTube can help athletic departments reach out to their fan base by posting 
video highlights of games, events, and interviews with players and coaches. Thus, YouTube helps an athletic department provide behind the scenes look at teams, events, and other fun activities. In addition, Mobile phones are increasingly popular for these purposes, because fans can $\log$ on to the Internet using their phones, send and receive text messages, and use sports apps (e.g., on the Apple iPhone) to keep up with the latest stats and stories about their favourite team.

Mediated sports spectatorship fulfils many functions for sports fans. As pointed out by Wenner and Gantz (1989), sport is a "near universal and nonthreatening conversation topic" (p. 242), enabling fans to establish commonality with other likeminded individuals. Watching sports allows fans to vicariously experience playing the sport and the thrill of competition without the risk of actual physical injury or loss (Raney, 2006). In a study of motives for viewing sports on television, Gantz (1981) found that "to thrill in victory" was the strongest motive. In identifying with teams and players, the line between fantasy and reality is blurred as fans come to see themselves as part of the team, basking in reflected glory after wins and cutting off reflected failure after losses (Cialdini, 2008). Social identification has also been found to affect people's media choices, in that individuals choose to view shows that bolster their identification with social groups important to them (Harwood, 1999). Studies by Hebdige (1981), Lull (1985), and Morley (1992) have also provided support for positive relationships between group memberships and media use. Social identity theory (Tajfel, 1978) has been widely applied to study sports fans' identification with teams. According to social identity theory, human behaviour ranges on a spectrum from purely interpersonal to purely intergroup (Tajfel \& Turner, 1986). In an interpersonal interaction, people relate to others as individuals, with no concept of social categories, and one's self-concept is defined by distinct individual cognitions, attitudes, 
beliefs, and emotions. Individuals are motivated to think and act in ways that achieve positive distinctiveness for the in-group, leading to high levels of intergroup differentiation and out-group derogation. For this to occur, one's group membership must be internalized, the social situation must allow for intergroup comparison, and the out-group should be relevant for comparison (Hogg, 2003). Because people are motivated to achieve and maintain a positive social identity, when joining a social group individuals will come to think of their in group as being superior to out-groups through positive intergroup differentiation.

Team identification unites fans as part of the in-group, providing them with feelings of belonging and solidarity, creating an "us versus them" atmosphere. Fans psychologically become part of the sports team they support, sharing in its glory of winning and agony of defeat. Sports fans express their affiliations with sport teams in several ways, including public displays of their fandom on personal Web sites, fan forums, and blogs (End, 2001); wearing team clothing (Madrigal, 2000); and following games fanatically throughout the season. Fans' self-evaluations often depend on the successes and failures of the team they support over the course of a season. These fans also most often rate other in-group members more favourably than out-group members and overestimate their team's number of wins (Wann \& Branscombe, 1993; Wann \& Dolan, 1994). Highly identified fans also strategically manipulate attributions after a loss to protect their social identity because they are not able to easily switch allegiances (Wann \& Branscombe, 1993). An early study by Mann (1974) found that fans of losing teams attributed game outcomes to external factors and were more critical of officials, perceiving plays as dirty. Miller and Ross (1975) found that fans internalized success and externalized failures. According to End, fans provide internal attributions for wins, such as player skills and coaching ability, and external attributions for losses, such as cheating by opponents, referee bias, and bad weather. They also use 
alternative strategies like blasting (derogating the opposition) and changing the dimension of comparison (e.g., wins over the season) to retain their positive social identity.

Studies have found that fans' self-esteem varies depending on whether their team is winning or losing, as well as on their identification level with the particular team. Hirt, Zillman, Erickson, and Kennedy (1992) found that fans of winning teams reported significantly higher self-esteem and better mood than fans of losing teams after a game and performed better on unrelated mental- and motor-skills tasks. Murrell and Dietz (1992) examined the impact of intergroup differentiation and self-esteem on team evaluations and found that fans who displayed greater in-group bias had higher self-esteem and evaluated the team more positively.

\section{HYPOTHESIS:}

H1a: MUPM (Media Use Printed Media) has a significant positive direct effect on SE (Self-esteem)

H1b: FI (Fan Identification) mediates the impact of MUPM on SE

H2a: MUBM (Media Use Broadcast Media) has a significant positive direct effect on SE H2b: FI mediates the impact of MUBM on SE

H3a: MUOM (Media Use online Media) has a significant positive direct effect on SE H3b: FI mediates the impact of MUOM on SE H4a: MUMP (Media Use Mobile Phones) has a significant positive direct effect on SE H4b: FI mediates the impact of MUMP on SE

The research question (R1): Does Fan identification mediate the relation between media use and fan self- esteem?

\section{METHODOLOGY}

The current study employed the warp PLS 3.0 technique, which works in a similar manner for other programs such as LISREL or EQS but is more appropriate with small 
samples to test the relationships between sports fan identification, collective self-esteem, and media use.

\section{PROCEDURES}

An online survey was constructed using Qualtrics.com, with measures for the variables tested. A link to the online survey was randomly sent through social media (Facebook), especially through groups relating to sports fans, to 275 participants. A total of 141 Egyptian participants (51.3\%) completed the survey.

Fan identification was measured using a modified version of the Sport Spectator Identification Scale (Wann \& Branscombe, 1993). Six questions measured fans' involvement with and psychological connection to a sports team using 7-point Likert-type scales. The media-use measure included 12 questions, with three questions for each type of media (print, broadcast, online, and mobile). Seven-point Likert-type scales were used to measure respondents' use of each type of media to find out about the team during football season. Print media included newspapers, magazines, and books. Broadcast media included television and radio. Online media referred to Internet use through personal computers and laptops and included Web sites, forums, and blogs. Mobile-phone media referred to mobile-phone use to access the Internet, text messaging, voice calls, and use of sports apps on PDAs. Collective self-esteem was measured using a modified version of Crocker and Luhtanen's (1990) Collective Self-Esteem Scale. A total of 16 questions, using 7-point Likert-type scales, assessed respondents' collective self-esteem pertaining to the school's football team.

\section{RESULTS}

Of the 141 respondents, 31 were women (22\%) and 110 were men (78\%). 3 participants $(2.1 \%)$ were 16 years or less, 64 participants $(45.4 \%)$ were between 17 to 22 years, 60 participants (42.6\%) were between 23 to 30 years, 14 participants $(9.9 \%)$ were 31 years or older. For year in school, 12 were secondary school students (8.5\%), 3 students 
(2.1\%) were intermediate education, 87 were undergraduate students $(61.7 \%), 38$ were postgraduate students $(27 \%)$, and I participant $(0.7 \%)$ had another education. In terms of socioeconomic status, 49 were from families with annual income about 2500 Egyptian pounds or less (34.8\%), 60 were from families with income from 2500 to 5000 Egyptian pounds (42.6\%), 16 were from families with income between 5001 to 10000 Egyptian pounds (11.3\%), 16 families were with income between 10000 Egyptian pounds and more (11.3\%) (Table 1).

Table 1. Demographic Information for the Sample (N=141)

\begin{tabular}{|c|c|}
\hline & Percent (n) \\
\hline \multicolumn{2}{|l|}{ Gender } \\
\hline Male & $22 \%(31)$ \\
\hline Female & $78 \%(110)$ \\
\hline \multicolumn{2}{|l|}{ Age } \\
\hline 16 or less & $2.1 \%(3)$ \\
\hline 17 to 22 years & $45.4 \%(64)$ \\
\hline 23 to 30 years & $42.6 \%(60)$ \\
\hline 31 years or older & $9.9 \%(14)$ \\
\hline \multicolumn{2}{|l|}{ Education } \\
\hline Secondary school & $8.5 \%(12)$ \\
\hline Intermediate education & $2.1 \%(3)$ \\
\hline Undergraduate & $61.7 \%(87)$ \\
\hline Postgraduate & $27 \%(38)$ \\
\hline Other education & $0.7 \%(1)$ \\
\hline \multicolumn{2}{|l|}{ Income: } \\
\hline 2500 or less & $34.8 \%(49)$ \\
\hline 2501 to 5000 & $42.6 \%(60)$ \\
\hline 5001 to 10000 & $11.3 \%(16)$ \\
\hline 10000 or more & $11.3 \%(16)$ \\
\hline
\end{tabular}

Initially, it was hypothesised that MUPM (Media Use Printed Media) has a positive and significant direct effect on SE (H1a: MUPM $\rightarrow$ SE) [Fig. 1], and that FI mediates the 
effect of MUPM on SE (H1b: MUPM $\rightarrow$ FI $\rightarrow$ SE) [Fig. 2]. Contrary to theoretical expectations, both H1a and H1b were not empirically supported (Table 2).

Table 2. Direct and Indirect Effect of Printed Media on Self-esteem

\begin{tabular}{|c|c|c|c|c|}
\hline $\begin{array}{l}\text { Investigated } \\
\text { relationship }\end{array}$ & $\beta(p$ Value $)$ & $\begin{array}{c}\% \text { of the total effect } \\
\text { (mediation magnitude) }\end{array}$ & $\mathrm{H}$ & Support? \\
\hline \multicolumn{3}{|l|}{$\mathrm{MUPM} \rightarrow \mathrm{SE}$} & & \\
\hline Total effect & $0.081(0.164)$ & $100 \%$ & & \\
\hline $\begin{array}{l}\text { Direct effect before } \\
\text { including FI }\end{array}$ & $0.078(0.175)$ & $100 \%$ & & \\
\hline $\begin{array}{l}\text { Direct effect after } \\
\text { including FI }\end{array}$ & $0.007(0.467)$ & $0.09 \%$ & $1 \mathrm{a}$ & No \\
\hline $\begin{array}{l}\text { Indirect effect via FI } \\
(\mathrm{MUPM} \rightarrow \mathrm{FI} \rightarrow \mathrm{SE})\end{array}$ & $0.074(0.104)$ & $\begin{array}{c}0.91 \% \\
\text { (No mediation) }\end{array}$ & $1 b$ & No \\
\hline
\end{tabular}

H1a: MUPM has a significant positive direct effect on SE

H1b: FI mediates the impact of MUPM on SE

Specifically, regarding H1a, it was found that MUPM had a negligible weight on SE

$(\beta=.007, p=.467)$ [Fig. 1]. Additionally, the FI's role in mediating the effect of MUPM on

SE was not empirically supported because of MUPM's insignificant direct effect on FI ( $\beta$ $=.094, p=.127)[$ Fig 2].

Figure 1. Direct Impact of Media Use on Self-Esteem

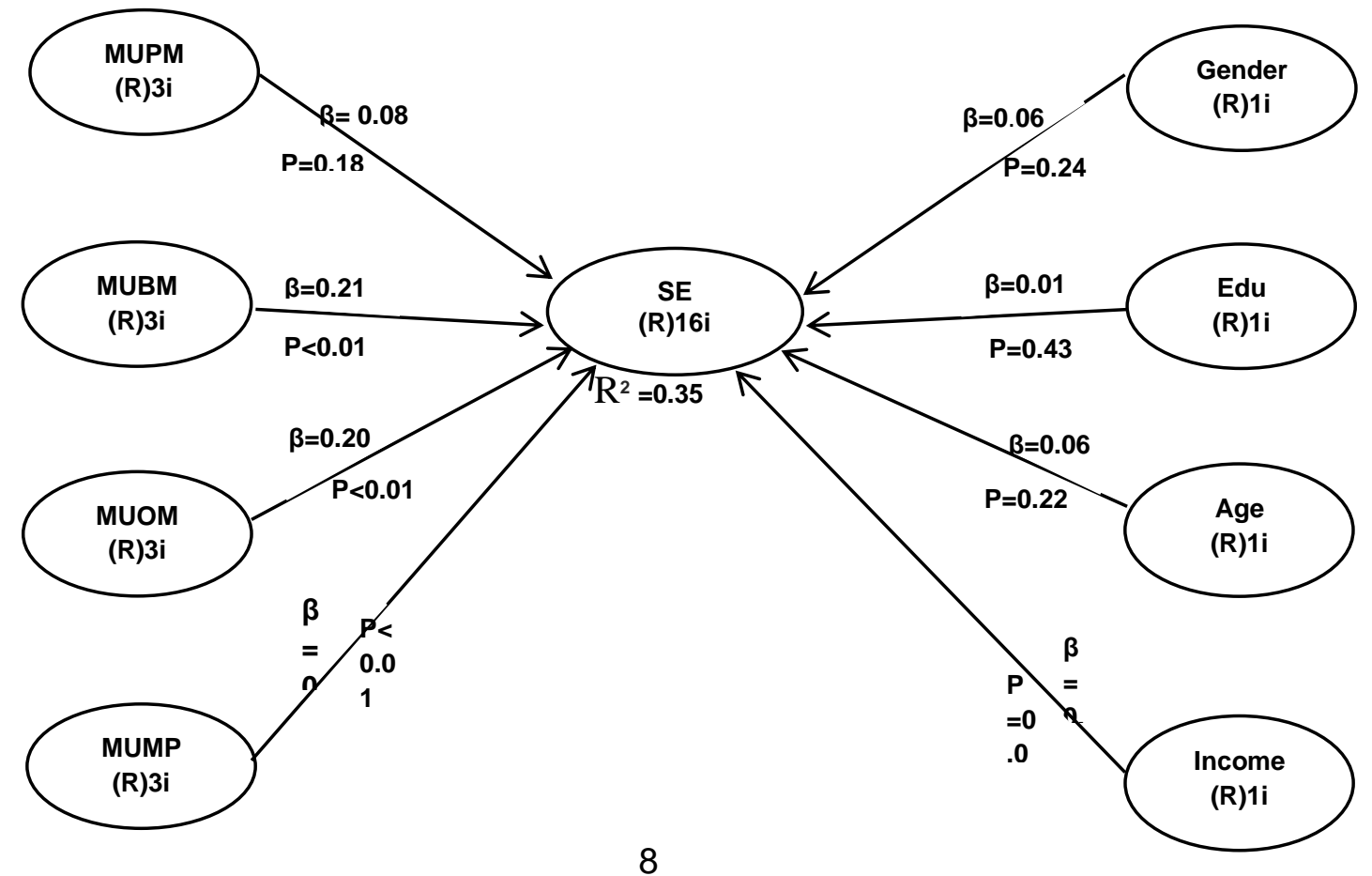


It was hypothesised that MUBM (Media Use Broadcast Media) has a positive and significant direct effect on SE (H2a: MUBM $\rightarrow$ SE) [Fig. 1], and that FI mediates the effect of MUBM on $\mathrm{SE}(\mathrm{H} 2 \mathrm{~b}: \mathrm{MUBM} \rightarrow \mathrm{FI} \rightarrow \mathrm{SE})$. On one hand, in disagreement with research hypothesis, $\mathrm{H} 2 \mathrm{a}$ was not empirically supported. On the other hand, H2b was empirically substantiated (Table 3, Fig. 2).

Table 3. Direct and Indirect Effect of Broadcast Media on Self-esteem

\begin{tabular}{c|c|c|c|c}
\hline $\begin{array}{c}\text { Investigated } \\
\text { relationship }\end{array}$ & $\beta(p$ Value $)$ & $\begin{array}{c}\text { \% of the total effect } \\
\text { (mediation magnitude) }\end{array}$ & $\mathrm{H}$ & Support? \\
\hline MUBM $\rightarrow \mathrm{SE}$ & \multicolumn{3}{|c}{} \\
\hline Total effect & $0.208(0.005)$ & $100 \%$ & & \multicolumn{2}{|c}{} \\
\hline $\begin{array}{c}\text { Direct effect before } \\
\text { including FI }\end{array}$ & $0.206(0.006)$ & $100 \%$ & $2 \mathrm{a}$ & No \\
\hline $\begin{array}{c}\text { Direct effect after } \\
\text { including FI }\end{array}$ & $0.004(0.480)$ & $0.02 \%$ & $2 \mathrm{~b}$ & Yes \\
\hline $\begin{array}{c}\text { Indirect effect via FI } \\
(\mathrm{MUPM} \rightarrow \mathrm{FI} \rightarrow \mathrm{SE})\end{array}$ & $0.203(<0.001)$ & $\begin{array}{c}0.98 \% \\
\text { (Full mediation) }\end{array}$ & &
\end{tabular}

H2a: MUBM has a significant positive direct effect on SE

H2b: FI mediates the impact of MUBM on SE

Specifically, regarding H2a, it was found that MUBM had a trivial weight on SE $(\beta=.004, p$ $=.480)$. Additionally, referring to $\mathrm{H} 2 \mathrm{~b}$, because $(\mathrm{MUBM} \rightarrow \mathrm{FI}: \beta=.259, p<.001),(\mathrm{FI} \rightarrow \mathrm{SE}: \beta$ $=.785, p<.001)$, and their product $(\mathrm{MUBM} \rightarrow \mathrm{FI} \times \mathrm{FI} \rightarrow \mathrm{SE}: \beta=.203, p<.001)$ were confirmed as significant, as well as $\mathrm{MUBM} \rightarrow \mathrm{SE}$ was reduced from $(\beta=.206, p=.006$; before the inclusion of the suggested mediator FI; (Fig.1) to $(\beta=.004, p=.480$; after its inclusion) with $(\beta=-.202)$, it was concluded that the suggested mediator FI had fully mediated the effect of MUBM on SE (MUPM $\rightarrow$ FI $\rightarrow$ SE: $\beta=.203, p<.001)$ [Fig. 2] 
Figure 2. Indirect effect of Media use upon Self-esteem through Fan Identification

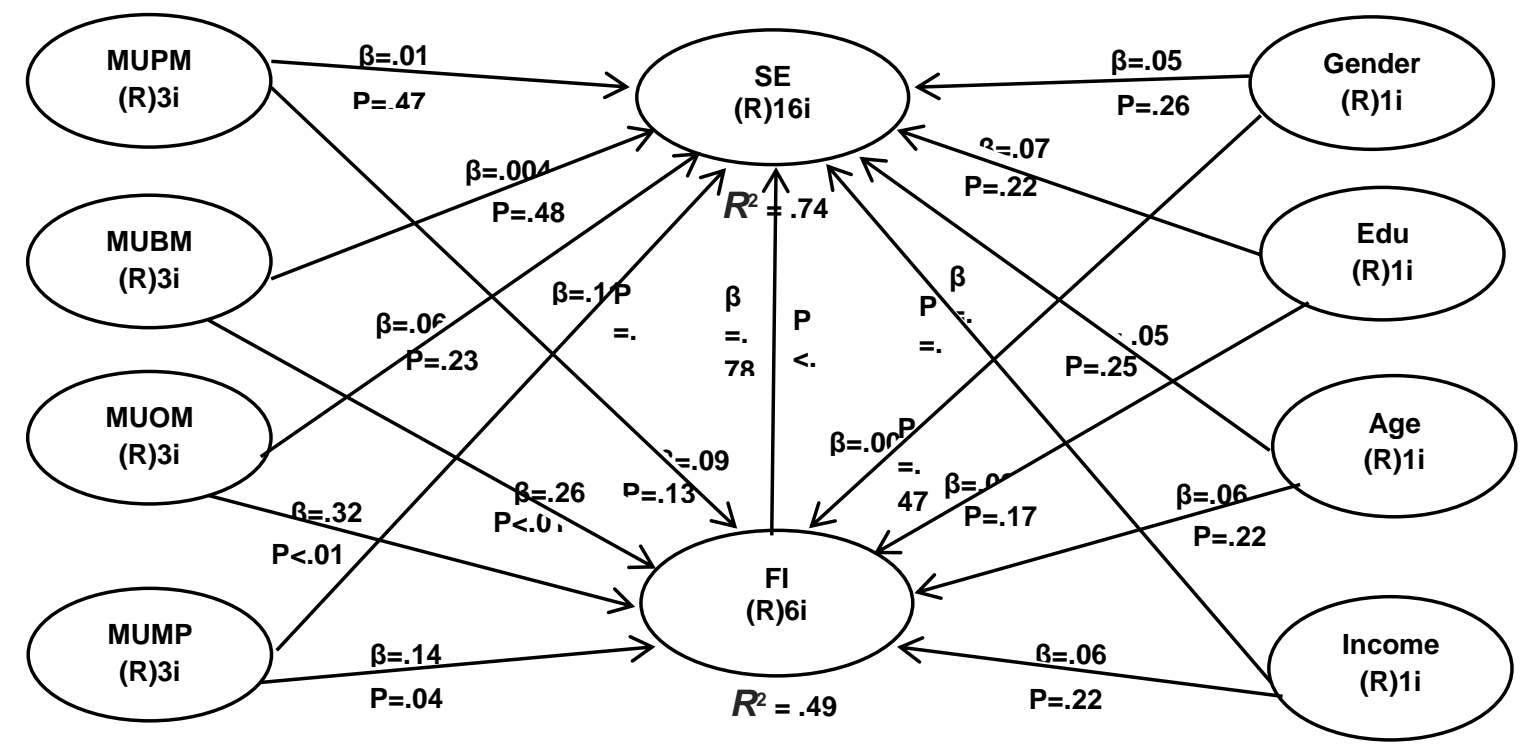

It was hypothesised that MUOM (Media Use Online Media) has a positive and significant direct effect on SE (H3a: MUOM $\rightarrow$ SE) [Fig. 1], and that FI mediates the effect of MUOM on SE $(\mathrm{H} 3 \mathrm{~b}: \mathrm{MUOM} \rightarrow \mathrm{FI} \rightarrow \mathrm{SE})$. On one hand, in disagreement with research hypothesis, H3a was not empirically supported. On the other hand, H3b was empirically substantiated (Table 4, Fig. 2).

Table 4. Direct and Indirect Effect of Online Media on Self-esteem

\begin{tabular}{|c|c|c|c|c|}
\hline $\begin{array}{l}\text { Investigated } \\
\text { relationship }\end{array}$ & $\beta(p$ Value $)$ & $\begin{array}{l}\% \text { of the total effect } \\
\text { (mediation magnitude) }\end{array}$ & $\mathrm{H}$ & Support? \\
\hline \multicolumn{5}{|l|}{$\mathrm{MUOM} \rightarrow \mathrm{SE}$} \\
\hline Total effect & $0.313(<0.001)$ & $100 \%$ & & \\
\hline $\begin{array}{l}\text { Direct effect before } \\
\text { including FI }\end{array}$ & $0.202(0.007)$ & $100 \%$ & & \\
\hline $\begin{array}{l}\text { Direct effect after } \\
\text { including FI }\end{array}$ & $0.060(0.234)$ & $0.19 \%$ & $3 a$ & No \\
\hline $\begin{array}{l}\text { Indirect effect via FI } \\
(\mathrm{MUPM} \rightarrow \mathrm{FI} \rightarrow \mathrm{SE})\end{array}$ & $0.253(<0.001)$ & $\begin{array}{c}0.81 \% \\
\text { (Full mediation) } \\
\end{array}$ & $3 b$ & Yes \\
\hline
\end{tabular}

H3a: MUOM has a significant positive direct effect on SE

H3b: FI mediates the impact of MUOM on SE 
Specifically, regarding H3a, it was found that MUOM had a trivial weight on SE $(\beta=.060, p$ $=.234)$. Additionally, referring to $\mathrm{H} 3 \mathrm{~b}$, because $(\mathrm{MUOM} \rightarrow \mathrm{FI}: \beta=.322, p<.001),(\mathrm{FI} \rightarrow \mathrm{SE}: \beta$ $=.785, p<.001)$, and their product $(\mathrm{MUOM} \rightarrow \mathrm{FI} \times \mathrm{FI} \rightarrow \mathrm{SE}: \beta=.253, p<.001)$ were confirmed as significant, as well as $\mathrm{MUOM} \rightarrow \mathrm{SE}$ was reduced from $(\beta=.202, p=.007$; before the inclusion of the suggested mediator FI; (Fig. 1$)$ to $(\beta=.060, p=.234$; after its inclusion) with $(\beta=-.142)$, it was concluded that the suggested mediator FI had fully mediated the effect of MUOM on SE $(\mathrm{MUOM} \rightarrow \mathrm{FI} \rightarrow \mathrm{SE}: \beta=.253, p<.001)$ (Fig. 2)

It was hypothesised that MUMP (Media Use Mobile Phones) has a positive and significant direct effect on SE (H4a: MUBM $\rightarrow$ SE), and that FI mediates the effect of MUMP on $\mathrm{SE}(\mathrm{H} 4 \mathrm{~b}: \mathrm{MUMP} \rightarrow \mathrm{FI} \rightarrow \mathrm{SE}$ ). On one hand, in disagreement with research hypothesis, H4a was not empirically supported. On the other hand, H4b was empirically substantiated (Table 5).

Table 5. Direct and Indirect Effect of Mobile Phones on Self-esteem

\begin{tabular}{|c|c|c|c|c|}
\hline $\begin{array}{l}\text { Investigated } \\
\text { relationship } \\
\end{array}$ & $\beta(p$ Value $)$ & $\begin{array}{c}\% \text { of the total effect } \\
\text { (mediation magnitude) }\end{array}$ & $\mathrm{H}$ & Support? \\
\hline \multicolumn{5}{|l|}{$\mathrm{MUMP} \rightarrow \mathrm{SE}$} \\
\hline Total effect & $0.219(0.004)$ & $100 \%$ & & \\
\hline $\begin{array}{l}\text { Direct effect before } \\
\text { including FI }\end{array}$ & $0.213(0.004)$ & $100 \%$ & & \\
\hline $\begin{array}{l}\text { Direct effect after } \\
\text { including FI }\end{array}$ & $0.106(0.100)$ & $0.48 \%$ & $4 \mathrm{a}$ & No \\
\hline $\begin{array}{l}\text { Indirect effect via FI } \\
(\mathrm{MUPM} \rightarrow \mathrm{FI} \rightarrow \mathrm{SE})\end{array}$ & $0.113(0.027)$ & $\begin{array}{c}0.52 \% \\
\text { (Full mediation) } \\
\end{array}$ & $4 \mathrm{~b}$ & Yes \\
\hline
\end{tabular}

H4a: MUMP has a significant positive direct effect on SE

H4b: FI mediates the impact of MUMP on SE

Specifically, regarding $\mathrm{H} 4 \mathrm{a}$, it was found that MUMP had a trivial weight on $\mathrm{SE}(\beta=.106, p$ $=.100)$. Additionally, referring to $\mathrm{H} 4 \mathrm{~b}$, because $(\mathrm{MUMP} \rightarrow \mathrm{FI}: \beta=.144, p=.040),(\mathrm{FI} \rightarrow \mathrm{SE}: \beta$ $=.785, p<.001)$, and their product $(\mathrm{MUMP} \rightarrow \mathrm{FI} \times \mathrm{FI} \rightarrow \mathrm{SE}: \beta=.113, p=.027)$ were confirmed as significant, as well as $\mathrm{MUMP} \rightarrow \mathrm{SE}$ was reduced from $(\beta=.213, p=.004$; before the inclusion of the suggested mediator FI; [Fig. 1] to $(\beta=.106, p=.100$; after its 
inclusion) with $(\beta=-.107)$, it was concluded that the suggested mediator FI had fully mediated the effect of MUMP on SE (MUMP $\rightarrow$ FI $\rightarrow$ SE: $\beta=.113, p=.027)$ [Fig. 2].

There was no positive effect of gender whether male or female on neither self- esteem nor fan identification $(\mathrm{p}>0.05 ; \mathrm{P}=0.26$ and $\mathrm{P}=0.17)$. Concerning age, it showed no significance too on both self-esteem and fan identification $(\mathrm{P}>0.05$ in both of them). Education also didn't prove any positive impact upon either self-esteem or fan identification with $\mathrm{P}>0.05$ in both cases. Finally, economy failed to have any significance with self-esteem and fan identification as $\mathrm{P}$ was $>0.05$ in its impact upon both of them.

\section{DISCUSSION}

Among the findings in this study, the most important is that fan identification moderates the association between media use and collective self-esteem (R1). Mediated sports spectatorship, as a communicative activity, allows sports fans to bond with other

Like minded fans, create a positive social identity through positive in-group distinctiveness and out-group derogation, and reinforce their fan experience by letting them more vividly experience their team's wins and losses throughout the season. Sports discourse can be both mediated and interpersonal in nature (Halone, 2008). Denham (2004) states that mediated sports spectatorship often reinforces intragroup similarities, especially for White, heterosexual male fans who "came of age in line with dominant, hegemonic constructions of masculinity" (p. 382), which athletes often embody.

A second significant finding of the current study is that among the four media types tested, Broadcast media, online media, and mobile phones had an indirect effect upon self-esteem through fan identification. Sports fans thereby use media to achieve and maintain their positive social identity through intergroup differentiation from rival teams and manage their feelings of self-worth through associating with a successful team. Mediated sports spectatorship, as a communicative activity, allows sports fans to bond with other like-minded 
fans, create a positive social identity through positive in-group distinctiveness and out-group derogation, and reinforce their fan experience by letting them more vividly experience their team's wins and losses throughout the season. Sports discourse can be both mediated and interpersonal in nature (Halone, 2008).

According to social identity theory, people inculcate the values and emotions of their in-group to create a shared identity and gain part of their self-concept from membership in the in-group (Tajfel \& Turner, 1986). This quest for positive distinctiveness is fulfilled by the numerous types of Web sites catering to sports fans. Online forums and message boards enable fans to publicly display their associations, make self-serving attributions, and employ self-enhancing strategies such as BIRGing and CORFing. League and team Web sites allow them to check the latest statistics and game schedules. On network sites (e.g., ESPN), they can stream videos and instant replays of games. On social-networking sites (e.g., Ballhype, Sports Fans Live) and blogs, they can even connect with other fans and send and receive upto-the-minute news about their favourite team and players. As Mean (2006) states, "sports is a powerful, familiar and highly naturalized discourse that has become more prominent with the extensive rise in media coverage over the past 15 to 20 years" (p. 67).

\section{CONCLUSION}

This study sought to extend current research on sports fans' strategic use of media to both maintain and enhance their identification with their favourite team. Results indicate that fan identification is a moderator in the relationship between media use and collective self-esteem. Of the four media types tested (print, broadcast, online, and mobile phones), broadcast media, online media, and mobile phones were found to have a positive indirect impact upon collective self-esteem. The implication of the current findings for media professionals, athletic administrators, and sports organizations is that they should consider 
using online media over other more traditional media types to best reach out to this large and fast-growing segment of sports fans.

\section{REFERENCES}

Bryant, J., \& Raney, A.A. (2000). Sports on the screen. In D. Zillmann \& P. Vorderer (Eds.), Media entertainment: The psychology of its appeal (pp. 153-174). Mahwah, NJ: Lawrence Erlbaum.

Cialdini, R.B. (2008). Influence: Science and practice. Glenview, IL: Scott Foresman.

Crocker, J., \& Luhtanen, R. (1990). Collective self-esteem and ingroup bias. Journal of Personality and Social Psychology, 58(1), 60-67.

Denham, B.E. (2004). Toward an explication of media enjoyment: The synergy of social norms, viewing situations and program content. Communication Theory, 14(4), 370-387.

End, C.M. (2001). An examination of NFL fans' computer mediated BIRGing. Journal of Sport Behaviour, 24(2), 162-182.

Gantz, W. (1981). An exploration of viewing motives and behaviours associated with television sports. Journal of Broadcasting, 25, 263-275.

Halone, K.K. (2008). The structuration of racialized sport organizing. The Journal of Communication Inquiry, 32, 22-42.

Harwood, J. (1999). Age identity and television viewing preferences. Communication Reports, 12(2), 123-136.

Hebdige, D. (1981). Subculture: The meaning of style. New York: Routledge.

Hirt, E.R., Zillman, D., Erickson, G.A., \& Kennedy, C. (1992). Costs and benefits of allegiance: Changes in fans' self-ascribed competencies after team victories versus defeat. Journal of Personality and Social Psychology, 63(5), 724-738

Hogg, M.A. (2003). Social identity. In M.R. Leary \& J.P. Tangney (Eds.), Handbook of self and identity (pp. 462-477). New York: Guilford Press.

Lull, J. (1985). On the communicative properties of music. Communication Research, 12, $363-372$.

Madrigal, R. (2000). The influence of social alliances with sports teams on intentions to purchase corporate sponsors' products. Journal of Advertising, 29(4), 13-25. 
Marketing Charts. (2009, August). Top 50 sites for August: Football fans rush online. Retrieved from http://www.marketingcharts.com/interactive/top-50-sites-for-august- 2009football-shopping-news-gain-steam-10443.

Mean, L.J. (2006). Making masculinity and framing femininity: FIFA, soccer and world cup Web sites. In H.L. Hundley \& A.C. Billings (Eds.), Examining identity in sports media (pp. 65-86). Newbury Park, CA: Sage.

Miller, D.T., \& Ross, M. (1975). Self-serving biases in the attribution of causality: Face of fiction? Psychological Bulletin, 82(2), 213-225.

Morley, D. (1992). Television, audiences and cultural studies. New York: Routledge.

Raney, A.A., \& Depalma, A.J. (2006). The effect of viewing varying levels and contexts of violent sports programming on enjoyment, mood and perceived violence. Mass Communication \& Society, 9(3), 321-338.

Real, M. (2006). Sports online: The newest player in Media sport. In A.A. Raney \& N. Bryant (Eds.), Handbook of sports and media (pp. 171-184). New York: Routledge.

Phua, J. J. (2010). Sports fans and media use: Influence on sports fan identification and collective self-esteem. International Journal of Sport Communication, 3, 190-206.

Sachoff, M. (2008, July 12). Serious sports fans spend more time online. Retrieved from http://www.webpronews.com/topnews/2008/07/21/ serious-sports-fans-spend-moretimeonline.

Tajfel, H. (1978). Social categorization, social identity and social comparison. In H. Tajfel (Ed.), Differentiation between social groups: Studies in the social psychology of intergroup relations (pp. 61-76). London: Academic Press.

Tajfel, H., \& Turner, J.C. (1986). The social identity theory of intergroup behaviour. In S. Worchel \& W. Austin (Eds.), Psychology of intergroup relations (pp. 7-24). Chicago: Nelson Hall.

Wann, D.L. (2006). Understanding the positive social psychological benefits of sport team identification: The team identification-social psychological health model. Group Dynamics: Theory, Research, and Practice, 10(4), 272-296.

Wann, D.L., \& Branscombe, N.L. (1993). Sports fans: Measuring degree of identification with their team. International Journal of Sport Psychology, 24, 1-17.

Wann, D.L., \& Dolan, T. (1994). Attribution of highly identified sports fans. The Journal of Social Psychology, 134, 783-792. 
Wann, D.L., Royalty, J., \& Roberts, A. (2000). The self-presentation of sport fans: investigating the importance of team identification and self-esteem. Journal of Sport Behaviour, 23(2), 198-208.

Wenner, L.A., \& Gantz, W. (1989). The audience experience with sports on television. In L.A. Wenner (Ed.), Media, sports \& society (pp. 241-269). Newbury Park, CA: Sage. 